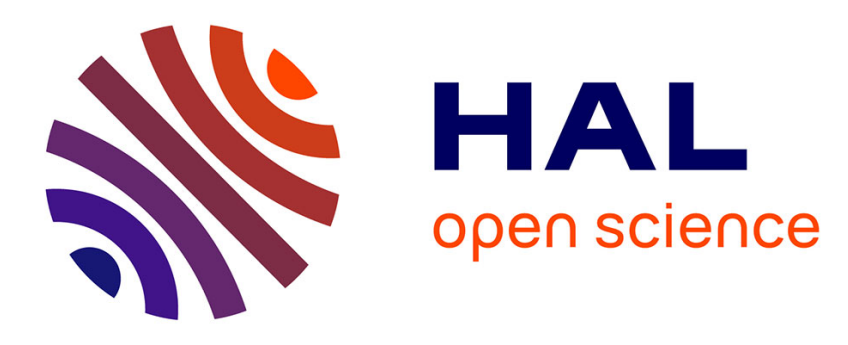

\title{
Discrete Event Simulation - A New Approach to Multi-level Capacitated Planning?
}

\author{
Ernst-August Stehr, Jan Reschke, Günther Schuh
}

\section{To cite this version:}

Ernst-August Stehr, Jan Reschke, Günther Schuh. Discrete Event Simulation - A New Approach to Multi-level Capacitated Planning?. IFIP International Conference on Advances in Production Management Systems (APMS), Aug 2018, Seoul, South Korea. pp.425-432, 10.1007/978-3-319-997049_52. hal-02164911

\section{HAL Id: hal-02164911 \\ https://hal.inria.fr/hal-02164911}

Submitted on 25 Jun 2019

HAL is a multi-disciplinary open access archive for the deposit and dissemination of scientific research documents, whether they are published or not. The documents may come from teaching and research institutions in France or abroad, or from public or private research centers.
L'archive ouverte pluridisciplinaire HAL, est destinée au dépôt et à la diffusion de documents scientifiques de niveau recherche, publiés ou non, émanant des établissements d'enseignement et de recherche français ou étrangers, des laboratoires publics ou privés. 


\title{
Discrete Event simulation - a new approach to multi-level capacitated planning?
}

\author{
Ernst-August Stehr ${ }^{1}{ }^{\square}$ Jan Reschke $^{1}$ and Günther Schuh ${ }^{2}$ \\ ${ }^{1}$ F.I.R. e.V. an der RWTH Aachen, Campus Boulevard 55, 52074 Aachen \\ ${ }^{2}$ Werkzeugmaschinenlabor WZL der Rheinisch-Westfälischen Technischen Hochschule \\ (RWTH) Aachen, Campus-Boulevard 30, 52074 Aachen \\ \{ernst-august.stehr, jan.reschke, guenther.schuh\}@fir.rwth- \\ aachen.de
}

\begin{abstract}
Discrete Event Simulation (DES) is a well-known approach to simulate production environments. However it was rarely used for operative planning processes and to our knowledge never in terms of multiple disposition levels. In this paper we develop the necessary adjustments to use DES for this purpose and show some theoretical advantages.
\end{abstract}

Keywords: Discrete Event simulation, advanced planning, production optimization, Multi-level production

\section{Introduction}

Companies strive for competitive advantages. With the proliferation of modern machinery the focus has changed to a higher relative importance of time-to-delivery, a reliable order promising and high utilization of expensive assets as quality and product features become more and more standard [1]. All these factors are highly influenced by the production planning. IT systems were developed and deployed in order to improve these functions. This started from material requirements planning (MRP) systems which do not consider capacities and recently advanced planning systems (APS) which do.

The acceptance of such software packages is somewhat limited as often companies experienced so called ERP-nervousness [2]. This term implies that the planning results - most importantly promised delivery dates - vary from planning run to planning run and leave customers and companies puzzled for a reliable deadline. On the other hand, Discrete Event Simulation (DES) - or more generally simulation - has been used for a long time to model uncertainties and provide reliable insights under stochastic conditions.

Before a literature survey is given, the next chapter will outline the problem and some generally applicable principles. In the literature survey we will consider briefly alternative solution approaches and their shortcomings before focusing on DES and its current lack of support for multi-level production planning. In the remainder we will present the solution approaches. 


\section{Problem description}

This paper focuses on job shops. The machines are grouped by their technological characteristics and not by the sequence of the jobs on hand as these might differ significantly. The production is described by a set of production orders, each consisting of a sequence of operations. Every operation requires a machine and an operator for a specific time. The operators are qualified only for some machines and not for others. Furthermore some operations have a bill-of-material which describes the required components.

The existence of significant setup times mandates the production of larger lot sizes which in turn mean that one production order might fulfill multiple demands. Therefore $n: m$ relationships between component manufacturing orders and assembly orders might exist and this is repeated over different levels of production. E.g. a set of hundreds of pistons is manufactured which in turn is used to produce different engines which are then used for multiple cars. We will refer to this as order networks, describing the component flow between different orders, and multi-level production.

The objective of any production planning algorithm must be to time the execution of the operations in such a way, that a) machines are utilized as much as possible b) stocks are kept to a minimum and therefore produced as late as possible c) deadlines for deliveries are met for the overall products.

While these objectives should be fulfilled in the best possible way the restrictions have to be taken into account: a) Material availability (no production can be scheduled before the components are ready) b) machine and personal capacity has to be available and c) may not be double-booked. Obviously deviations from the plan will happen and must therefore be buffered against which increases stock levels and reduces overall efficiency.

\section{$3 \quad$ Literature survey}

\subsection{Classical approaches without simulation}

Many companies use an MRP like system [3]. These systems generate assembly orders for the customer orders and derive secondary demands from the bill-ofmaterial information. In order to do so, they sort all materials by their disposition level and calculate for each level the demand. In terms of timing they assume a fixed lead time per material or operation. This approach however does not take the actual capacity into account and therefore generates invalid plans [4]. Additionally small changes in available quantities have significant impact on the deadlines [5].

Another approach is to use linear optimization programs that depict the capacity as a set of equations where the sum of all processing times in a period may not exceed a threshold [6]. These systems are computationally complex and therefore often have to be very simplified models of reality.

A well utilized approach is job-based-sequencing [7, 8]. In this approach the final orders are sorted by their creation date. The algorithm works its way backwards from 
the last to the first operation and finds a slot in the Gantt-chart of a machine where to plan the order. If components are needed, they are scheduled in the same way. However, this approach has multiple draw-backs:

- As the free slots get smaller and smaller, large operations cannot be scheduled in and require the system to find a slot with long lead times

- For the same reason a minor disruption needs to find a new slot which might differ significantly from the previously assigned slot, so small changes result in disproportionally large shifts of overall planned deliveries.

- Once the system comes into the past it switches to a forward calculation, but usually it does not change the already scheduled sub-components which are therefore delivered too early.

\subsection{Priority based (simulation) approaches}

Another approach is based on priority rules. In every situation the sequence is built by ordering the operations according to a simple rule. These approaches are often used for "Leitstand"-type systems which only plan short term operations but take the earliest start and latest end date per order from another (MRP)-system.

A number of works starting in the 1960 have analyzed the effect of priority rules on certain target objectives. An excellent overview is given by Ramasesh [9]. In this paper among others the coordination of multiple components in an assembly job is proposed via means of different rules which assign priorities based on the question whether an order is on a critical path or not. However, this implicitly assumes that the assignment of component orders to the assembly order is fixed and known in advance. In contrast classical approaches are able to reassign material reservations and thus use an additional degree of freedom to optimize performance.

A specific implementation of this is discrete event simulation that uses priority rules to simulate the passage of time $[10,11]$. There at every time step the most urgent job is scheduled on a machine. The end of a job or a shift is an event which triggers the selection of the next job from the queue. This might include Kanban-like material systems, in which the event "out-of-stock" generates a new production order. This does not include the handling of "push"-type orders for which no regular stock is held as is the case in manufacturing-to-order environments. The name is unfortunate, because it mixes the algorithm (prioritized queues, event based processing) with the purpose simulation. However, the algorithms yields dates for each operation and therefore the same result as classical day-to-day planning approaches.

Yet, these systems are focused very much on high-level capacity and strategy analysis instead of a productive scheduling [12]. The few exceptions were generally in the semi-conductor field $[13,14]$ where very complex routings have to be faced, yet material availability and therefore order networks are not needed.

Some approaches have tried to combine simulation approaches with other systems. Some authors use simulation results considering capacity to adopt the lead times of MRP-like systems [15, 16]. Graves and Milne propose a way to schedule the order release based on previous simulation results by allowing a maximum threshold of 
time in the system [17]. Again other works combine DES with optimization approaches, typically meta-heuristics as genetic algorithms or simulated annealing. None of these use the DES as a full production planning program in its own right [11, $14,15]$.

\subsection{Summary of literature survey}

Table 1. Comparison of approaches in literature

\begin{tabular}{|l|l|l|l|}
\hline Criteria & DES & Classical & This paper \\
\hline Calculates dates on operation level & Yes & Yes & Yes \\
\hline Reduces nervousness & Yes & No & Yes \\
\hline Used for day-to-day planning & Rarely & Yes & Yes \\
\hline $\begin{array}{l}\text { Copes with multiple disposition levels } \\
\text { as stand-alone tool }\end{array}$ & No & Yes & Yes \\
\hline
\end{tabular}

A vast body of literature exists on a number of classical, non-simulation based planning solutions. But small deviations lead to massive changes in the planning result (Nervousness). On the other hand Discrete Event Simulation has been used successfully in highly uncertain environments as strategic planning and factory design. However, it was mostly limited to that role. Again there are many such papers.

There are far fewer papers for the usage of DES in day-to-day production planning, but these fall in two categories: a) Scheduling single-level productions or b) the combination of DES with other systems, e.g. genetic algorithms or simulated annealing or MRP systems. Both approaches follow the hierarchical planning paradigm in which capacity and material are planned separately.

This paper shall develop a system based on DES, which uses the inherent stability, but extends it towards the requirements for a day-to-day planning in multiple disposition levels. This is not trivial for reasons given in the solution part.

\section{Solution approach}

In this article a system based on a discrete event simulation was developed to work on multi-level-order networks. The implementation was done in Java. The data model consists of orders which (with the exception of customer orders) deliver a material to stock and contain a number of operations. These operations require a machine for a certain processing time and a minimum time between operations for transport. The machine itself needs a qualified person from a pool. The operators have a set of shifts in which they can work. The start and end of a shift as well as the start and end of the processing of an operation are depicted as events in the DES. Additionally the end of an order triggers the start of succeeding operations of other orders. Some of the additional, novel aspects needed for an operative planning are described in the following part. 


\subsection{The due date problem}

The due dates are calculated by a fixed lead time which is calculated backwards from customer orders to its components. The resulting deadline might be in the past as it is only used for the priority rules, not the actual calculation of planned dates. While conventional due dates consist of just one date, the operative planning required a split between the wish of the customer (often unrealistic, but the earliest allowed delivery time) and the order promise date which results from the first capacitated planning run. Therefore an internal synthetic date is used as due date. This is calculated as follows: As long as the (simulation) time is before the promised date (calculated backward from the last to the first operation with fixed lead time), the wished date is used. However, once the promised date is before the simulation time, so that the order is getting urgent, than the promised date is used minus a large surcharge (e.g. 10 years) to make sure that promised orders have higher priorities than a mere wish. This additionally allows having different surcharges for different customers, yet keeping the capacity available unless the due date is really in danger.

\subsection{The order release problem}

As a DES is a forward calculating system the order release is a major problem. Without such a mechanism it would flush all orders immediately into the (simulated) production. However, it became clear in first experiments that low priority orders finish their operations more or less regardless when they are released. This happens because the relative order of the due dates and the capacity constraints just lead to a longer waiting time. Therefore the date results (last Plan $=\mathrm{LP}$ ) from one planning run are used to determine the order release as a fixed lead time before the next run. Therefore only a fixed advancement for the LP is allowed. Experiments show very little deviations between the planning runs despite vastly different order release times. In the second planning run orders are often released weeks after the results from the first run. Consecutively they finish the first operations much faster, but at the bottleneck (and one operation is always the bottleneck) and after the difference mostly is down to a few minutes.

While this logic discusses only the order release based on bottlenecks in later operations and has little advantages over CONWIP (constant level of Work-in-progress) or other mechanisms here, it can be extended to order networks. In this case a late assembly (e.g. because of a late purchase order) allows the manufacturing of components only a fixed lead time in advance of the calculated planned date. In other words: In a first simulation run all orders are released quite early (only restricted by the wishdate). A late purchase order or a capacity bottleneck results in a late delivery (despite potentially a high priority). This information is used to withhold the order release in the second run for a fixed lead time of the date calculated in the first run. This second run takes place immediately after the first run and together they form a production plan. As discussed analysis shows that despite large differences in order release times the final outcome does virtually not change. 


\subsection{The material availability}

At the core of the system is the ability to account for material not yet on stock or in other words the capacitated, simultaneous planning of multiple disposition levels. The actual check for the availability is quite simple: The bill of material for an operation is known and its start is only allowed once all requirements are fulfilled.

Also the assignment of material to one of multiple, competing demands can just be handled in the same way as any other priority rule for capacities. However the priorisation of production orders becomes much more complex and is subject to ongoing experiments.

In a discrete event simulation the speed of the processing of an order depends on the priority an order has. This priority in turn depends on the usage. So a production order which is only delivered to stock will have a lower priority and hence slower progress than an order used for an urgent customer order. Thus unwanted and hard to solve feedback loops are happening where changes in the assignment of material reservations have impact on the planned dates and therefore the database of the assignment. We will report hopefully in the near future on progress on this topic.

\section{$5 \quad$ Evaluation}

The developed system is used by an industrial company in a real-world example since 2016. Before the introduction of the new DES-based system a Job-based-sequencing (JBS) was used. The company has roughly 400 employees, thereof 100 in direct manufacturing. The monthly revenue is ca. 5 million $€$, the total order book contains 4000 customer orders with 20 million $€$ worth. Every day 30.000 manufacturing operations are planned within less than a minute (JBS needed hours). The planning results in terms of revenue, utilization etc. are approximately comparable between JBS and DES and obviously depend strongly on the production environment.

After the rollout of the new system the actual delivery performance (\# of orders delivered on time) increased from $75 \%$ to $85 \%$.

To separate the real-world influences from planning performance the planning results for two consecutive days were compared. 3.488 identical customer orders were planned on both days. After this one day DES had 136 delayed orders (3.9 \%) compared to the previous planning run. However, only $46(1.32 \%)$ were delayed by more than one day so that a small change had a disproportionate effect. The respective figures for the JBS were $22 \%$ and $5 \%$ and therefore worse by a factor of 4-5.

\section{Conclusion and outlook}

Production planning and scheduling remain important, yet not fully satisfactory solved problems. One of the most pressing one is the nervousness, defined as a permanent change of planned delivery times from planning run to planning run despite only modest changes of the input. Existing systems tend to increase this problem while discrete event simulation from its base in simulation under highly unreliable 
and stochastic data promises a better performance in this way. However the usage of multiple production echelons requires many changes to the original idea of a DES.

The separate train of thoughts of simulation experts and operative planners has so far inhibited the development of such extensions to the algorithms. While our solution is not yet fully finished we have some very promising indications. This includes apparently a much more robust planning result especially compared to job based sequencing. The outlook is therefore twofold:

- To fully develop a system to improve the material reservation in a multi-level production environment. This has to focus on the priorisation of component orders and the (re)-assignment of demand material reservations under the framework of a DES.

- Further evaluation of the complete system against a set of performance criteria, namely the quality of the plan (measured in utilization and output, tardiness, stock levels and so forth) and the stability of the plan (measured in the change of planned delivery dates under defined levels of changed input).

\section{References}

1. Schuh und Stich: Produktion am Standort Deutschland. VDMA (2013)

2. Hauptvogel, A.: Bewertung und Gestaltung von cyber-physischer Feinplanung. Zugl.: Aachen, Techn. Hochsch., Diss., 2015, 1st edn. Ergebnisse aus der Produktionstechnik Produktionssystematik, vol. 2015,6. Apprimus-Verl., Aachen (2015)

3. Orlicky, J.: Material requirements planning. The new way of life in production and inventory management. McGraw-Hill, New York (1975)

4. Tempelmeier, H.: Material-Logistik. Modelle und Algorithmen für die Produktionsplanung und -steuerung in Advanced Planning-Systemen, 6th edn. Springer, Berlin (2006)

5. van DONSELAAR, K.: The use of MRP and LRP in a stochastic environment. Production Planning \& Control, 239-246 (1992)

6. Helber, S.: Operations-Management-Tutorial. [ein Anfänger-Lehrbuch zum Operations-Management für alle, die auch gerne Formeln mögen]. Helber, Hildesheim (2014)

7. Dickersbach, J.T., Keller, G.: Produktionsplanung und -steuerung mit SAP ERP. [umfassendes Handbuch zur Diskreten Fertigung mit SAP ; Prozesse und Customizing von PP verständlich erklärt ; mit Informationen zu Sonderbeschaffungsformen und der Integration mit SAP APO], 3rd edn. SAP Press. Galileo Press, Bonn (2012)

8. Hoppe, M.: Bestandsoptimierung mit SAP. [Mit SAP ERP und SAP SCM Bestände optimieren und Bestandskosten senken ; Prognosegenauigkeit und Planung verbessern ; mit zahlreichen Praxisbeispielen], 3rd edn. SAP betriebswirtschaftlich. Galileo Press, Bonn (2012)

9. Ramasesh, R.: Dynamic job shop scheduling: A survey of simulation research. Omega, 43-57 (1990) 
10. Bangsow, S.: Praxishandbuch Plant Simulation und SimTalk. Anwendung und Programmierung in über 150 Beispiel-Modellen. Hanser Verlag, München (2011)

11. Dangelmaier, W., Laroque, C., Klaas, A. (eds.): Simulation in Produktion und Logistik 2013. [Entscheidungsunterstützung von der Planung bis zur Steuerung ; 15. ASIM Fachtagung] ; Paderborn, 09. - 11. Oktober 2013. ASIM-Mitteilung, vol. 147. Heinz-Nixdorf-Inst. Univ. Paderborn, Paderborn (2013)

12. Simini et. al.: Proceedings of the 38 th conference on Winter simulation. Winter Simulation Conference, s.l. (2006)

13. Klemmt, A.: Ablaufplanung in der Halbleiter- und Elektronikproduktion. Hybride Optimierungsverfahren und Dekompositionstechniken. Zugl.: Dresden, Techn. Univ., Diss., 2011. Vieweg+Teubner Verlag, Wiesbaden (2012)

14. März, L., Krug, W., Rose, O., Weigert, G.: Simulation und Optimierung in Produktion und Logistik. Springer Berlin Heidelberg, Berlin, Heidelberg (2011)

15. Leypold et. al.: Integrierte Materialflusssimulation zur dynamischen Produktionsplanung und -steuerung (IsiPS). Abschlussbericht AiF-Vorhaben KF 0444 $601 \mathrm{KSS} 2$ (2003)

16. Moon, Y.B., Phatak, D.: Enhancing ERP system's functionality with discrete event simulation. Industr Mngmnt \& Data Systems, 1206-1224 (2005)

17. Graves, R.J., Milne, R.J.: A new method for order release. Production Planning \& Control, 332-342 (1997) 